\title{
LA EDUCACIÓN SEXUAL EN LA ESCUELA PRIMARIA: INTENTO FRUSTRADO DE LOS EUGENISTAS
}

\section{Carmen Diego Pérez}

cdiego@uniovi.es

Universidad de Oviedo
Montserrat González Fernández

montseg@uniovi.es

Universidad de Oviedo

Recibido: 28-02-2014

Aceptado: 15-03-2014

\section{Resumen}

Presentamos un estudio de carácter histórico-educativo sobre los debates en torno a la reforma sexual planteada en España en las primeras décadas del siglo XX y su repercusión en la educación sexual de la infancia. Recuperamos las opiniones que médicos y maestros hicieron públicas en diarios y revistas, así como el papel de varias sociedades que estimularon la publicación de obras sobre educación sexual destinadas al magisterio y a los escolares. A pesar de estas iniciativas, no se consiguió introducir en el plan de estudios de la Escuela Normal ni en la escuela primaria una asignatura específica sobre esta temática, situación que aún continúa.

Palabras clave: Eugenesia, educación sexual, coeducación, escuela primaria, España, Historia de la Educación.

\begin{abstract}
We present a study of historical and educational nature of the discussions around sexual reform proposed in Spain in the early decades of the $20^{\text {th }}$ century and its impact on the childhood sexual education. We achieved the opinions of doctors and teachers published in newspapers and magazines, as well as the role of several associations that encouraged the publication of works on sex education directed at teachers and children. These initiatives did not manage to introduce in the study plan of the college of education or the primary school a specific subject, situation still carried on.
\end{abstract}

Key words: Eugenics, sexual education, co-education, elementary school, Spain, History of Education. 


\section{Introducción}

La investigación histórica ha reconstruido la trayectoria de la eugenesia, sus conexiones y sus singularidades en España, la distinta utilización por variados regímenes políticos hicieron de ella, así como las relaciones entre eugenesia, educación sexual y maternidad (Álvarez, Aresti, Barrachina, Del Cura, Huertas, Lázaro, Nasch, Polo, Seoane, Vázquez y Moreno). En el caso de la educación sexual de la infancia no hay aún una literatura específica y esta cuestión se encuentra dispersa en obras de historia de la sexualidad, del feminismo, de la medicina, de la psiquiatría, de la psicología y el presente trabajo quiere iniciar una aproximación a la misma desde el ámbito pedagógico. Todas las investigaciones han aludido directa o indirectamente a la pedagogía, sin embargo, la difusión de las prácticas eugénicas en la escuela, o la recepción de estas por el magisterio requiere aún atención: ¿qué propuestas se hicieron desde la eugenesia?, ¿qué autores abordaron estas cuestiones?, ¿qué información proporcionó la prensa pedagógica a los docentes?, ¿se abrió paso a la educación sexual en las escuelas?, éstas son algunas de las cuestiones a las que intentamos dar respuesta en este artículo, en el que presentamos las condiciones en que estaba la educación sexual en nuestro país durante las cuatro primeras décadas del siglo XX.

\section{Las propuestas sobre educación sexual}

En España, a principios del siglo XX, médicos, juristas, sociólogos, sacerdotes y maestros fueron haciendo públicos varios discursos sobre la sexualidad que, en la década de los treinta, permitieron hablar de un movimiento de reforma sexual. Algunos de estos profesionales, convencidos eugenistas, empezaron a demandar una ilustración sexual de carácter científico. La eugenesia, que propugnaba el matrimonio consciente, higiénico o eugénico, con vistas a logar el mejoramiento de la raza coincidió, en estas medidas, con el movimiento regeneracionista que se desarrolló en la misma época (Álvarez: 1985). En esta línea, la principal problemática de la reforma eugénica fue atajar la cantidad de enfermedades que padecía la mujer trabajadora y la gran mortalidad infantil, según afirmaba el médico y eugenista Martí Ibáñez (1937). No es extraño, pues, que la eugenesia tuviera como principal 
vía de entrada en España la medicina y, dentro de ella, la pediatría y puericultura. Raquel Álvarez, experta en el estudio de la eugenesia, afirma que la atención a la infancia fue lo esencial de la eugenesia española que quería evitar la mortalidad infantil, una de las mayores preocupaciones, con "la regulación, control o simplemente educación de la sexualidad y la procreación” (Álvarez, 2004:63). Ya lo había expresado así el maestro y reconocido eugenista Luis Huerta: "sea el hogar pobre, sea el hogar rico, hoy la familia está incapacitada para dar al mundo hijos eugénicos" (1929b:25), por lo que vieron necesario iniciar una labor divulgadora en la que participaron pediatras, tocólogos, puericultores, psiquiatras y maestros que canalizaron sus acciones a través de varias sociedades.

Una primera iniciativa fue la creación en 1919 del Instituto de Medicina Social, que tuvo su domicilio en el Ateneo Científico-Literario de Madrid. Fue promovido por el médico Antonio Aguado Marinoni y entre los socios fundadores estaba el citado maestro Luis Huerta junto con abogados, ingenieros y médicos (César Juarros, Antonio Piga, Sebastián Recasens, Gustavo Pittaluga, Gregorio Marañón, Manuel Tolosa Latour, Antonio Dubois,...). Su objetivo fue abordar el estudio científico y práctico de toda clase de investigaciones médico-sociales. Tres meses después de aprobado su Reglamento, el Instituto publicó la Cartilla Popular de Medicina social redactada precisamente por Aguado Marinoni y por Luis Huerta, en la que planteaban la necesidad de enseñar a engendrar hijos sanos, pues "al bienestar de la raza interesa más la calidad que la cantidad de los hijos"1. Los más de 500 socios que tuvo durante su primer año de vida hicieron una importante labor de propaganda, si bien parece que esta institución no llegó más allá de 1923 (Álvarez, 1988:349), sí hubo otras iniciativas de gran repercusión en las que participaron muchos de sus miembros.

Uno de los acontecimientos que captó más la atención tanto de las autoridades políticas y religiosas como del pueblo en general fue la celebración en Madrid del Primer Curso Eugénico, promovido por la Sociedad Amigos del Niño en 1927 y organizado a partir de la conferencia pronunciada en la citada sociedad por Julio Noguera, profesor de Anormales del Estado y de la Beneficencia Municipal de Madrid, que habló de "La defensa de la raza en el niño". Se programaron diez conferencias, una por semana, que se iniciaron en febrero de 1928 en la Facultad de Medicina. Una vez terminada cada conferencia se hacía un resumen

\footnotetext{
${ }^{1}$ Se publicó en Madrid, por la Imprenta de Gabriel López del Horno, en 1919. Está también reproducida íntegramente en Rodríguez Ocaña, Esteban (1987): La constitución de la Medicina Social como disciplina en España (1882-1923). Madrid: Publicaciones, Documentación y Biblioteca Ministerio de Sanidad y Consumo, pp. 241-265.
} 
radiofónico, emitido por Unión Radio, que fue retransmitido en francés por la Estación de T. S. H. de la Torre Eiffel de Paris (Huerta, 1928). La segunda conferencia, "El aspecto jurídico de la maternidad consciente" de Luis Jiménez de Asúa, en la que defendía los anticonceptivos, rechazaba la reglamentación de la prostitución por entender que era una desgracia y no un crimen, cuestionaba la indisolubilidad del matrimonio, etc. desencadenó los ataques de dos periódicos católicos, El Debate y El Siglo Futuro, que consideraron escandalosos los temas abordados. El estado de opinión creado consiguió que sólo se pronunciaran media docena de las conferencias programadas, pues Primo de Rivera prohibió la celebración de las siguientes basándose en que eran impropias para un público no profesional y con la Real Orden de prohibición quería evitar que se convirtieran "en propaganda contra la natalidad, en regodeo pornográfico, ni en ofensa ni ataque contra la moral cristiana y los fundamentos éticos de la sociedad con el consiguiente estrago entre los jóvenes que escuchan tan perniciosas teorías" ${ }^{\text {. }}$. Dos de las cuatro conferencias que no se pudieron pronunciar estaban a cargo de dos religiosos: el jesuita José A. de Laburu, quien iba a hablar sobre "Pensamiento católico ante los problemas eugenésicos" y el vicario castrense, Francisco Sureda, con una conferencia sobre la sensualidad. Estos dos conferenciantes se retiraron del Curso por las presiones de la jerarquía eclesiástica ante el debate público generado, no obstante, su presencia inicial demuestra que las diversas tendencias ideológicas fueron contempladas en la programación de dicho Curso y a todas les interesaban estas cuestiones.

Las iniciativas eugenésicas y de educación sexual provocaron que la iglesia católica empezase a prestarles más atención. Fueron dos religiosos, el jesuita Ramón Ruiz Amado y el sacerdote Andrés Manjón, ambos vinculados a la enseñanza, quienes contribuyeron a la difusión de la educación para la castidad, que previamente había sido defendida desde criterios médicos e higiénicos para luchar contra la extensión de las enfermedades venéreas (Seoane, 2006:54). Ruiz Amado era partidario de retrasar la instrucción de los jóvenes en estas cuestiones y de impedir el acceso a estos conocimientos por medio de libros o por las explicaciones dadas en común o en la escuela, porque, entendía, atentaban contra el pudor. Igualmente Manjón, defendía la ignorancia del niño mientras se pudiera, exaltando los valores de la castidad y la continencia.

\footnotetext{
${ }^{2}$ Real Orden de 17 de marzo de 1928, Gaceta de Madrid, nº 82, 22 de marzo de 1928. Sobre este asunto véase Huerta, 1928; Noguera y Huerta, 1934 y Barrachina, 2004.
} 
El rechazo de la iglesia católica a la educación sexual fue frontal desde 1929, al tratar en la Carta Encíclica Divini illius Magistri sobre la Educación Cristiana de la Juventud, Pío XI la condenó, rechazando que el estado tuviera el monopolio de la educación y se opuso al naturalismo pedagógico por considerarlo perjudicial especialmente en la llamada educación sexual:

“49. Peligroso en sumo grado es, además, ese naturalismo que en nuestros días invade el campo educativo en una materia tan delicada como es la moral y la castidad. Está muy difundido actualmente el error de quienes, con una peligrosa pretensión e indecorosa terminología, fomentan la llamada educación sexual, pensando falsamente que podrán inmunizar a los jóvenes contra los peligros de la carne con medios puramente naturales y sin ayuda religiosa alguna; acudiendo para ello a una temeraria, indiscriminada e incluso pública iniciación e instrucción preventiva en materia sexual, y, lo que es peor todavía, exponiéndolos prematuramente a las ocasiones, para acostumbrarlos, como ellos dicen, y para curtir su espíritu contra los peligros de la pubertad".

Dos años más tarde, en 1931, la Sagrada Congregación del Santo Oficio condenó de nuevo las entonces modernas doctrinas sobre la educación sexual -que se habían extendido especialmente por Francia y Alemania- por querer instruir a cierta edad a los jóvenes en los fenómenos de la generación y a "la Eugenesia, tanto positiva como negativa, calificándola de contraria a las normas de la Iglesia, al derecho natural y a la personalidad de los individuos" ${ }^{3}$, remitiendo a lo preceptuado en la citada Encíclica. Tampoco aprobaba "los escritos y publicaciones que, para defender el nuevo método, han aparecido principalmente en los últimos tiempos, debidos aun a autores católicos".

Con la llegada del gobierno republicano, la reivindicación de una educación sexual se vio favorecida con la creación, en 1932, de la sección española de la Liga Mundial para la Reforma Sexual sobre bases científicas, presidida por Gregorio Marañón y de la que formaban parte médicos e intelectuales como César Juarros, Vital Aza, Quintiliano Saldaña, Jiménez de Asúa, etc. La secretaria de esta Liga fue la joven Hildegart ${ }^{4}$, que la había impulsado junto con

\footnotetext{
${ }^{3}$ Véase $A B C$, domingo 22 de marzo de 1931, p. 43. Cf. el decreto del Santo Oficio sobre Educación sexual y eugenesia, de 18 de marzo de 1931.

${ }^{4}$ Pocas son las mujeres con un papel relevante en el tema de la reforma sexual, por eso merece ser destacada Hildegart (seudónimo de Carmen Rodríguez), asesinada por su madre en 1933 cuando tenía 19 años, quien a pesar de su corta vida ya había publicado varias obras de esta temática: Sexo y amor.
} 
su madre, Aurora Rodríguez. Esta Liga se articulaba en secciones: "Eugenesia"; "Feminismo y Matrimonio"; "Legislación"; "Prostitución y Profilaxis Venérea" y "Pedagogía sexual", atendida esta última por Luis Huerta y José Bugallo, quienes tenían obra publicada sobre esta temática. Fue precisamente esta Liga la que organizó, junto con la Asociación Profesional de Estudiantes de Medicina y la Gaceta Médica Española, las Primeras Jornadas Eugénicas Españolas (como continuadoras del fallido Curso Eugénico de hacía un lustro), celebradas en Madrid entre el 21 de abril y el 10 de mayo de 1933 y presididas por el Ministro de Instrucción Pública Fernando de los Ríos. El comité organizador había previsto la presencia de dos maestros, Luis Huerta representando a Gaceta Médica Española y Rodolfo Tomás Samper, por parte de la Liga. Dentro de estas Jornadas se programaron cursillos técnicos, tratando el de "Pedagogía y Eugénica” el tema general "Educación sexual en el hogar y en la escuela” y en él Samper desarrolló los temas "El problema sexual en las comunidades escolares" y "La sexualidad en la orientación profesional" y Huerta los de "La cultura eugénica en relación con la edad escolar" y "Enseñanza de la Eugenesia en la Escuela Normal" (Noguera y Huerta, 1934).

Además de esta actividad de difusión, la Liga publicó desde su creación la revista Sexus en la que abordó la educación sexual, pues, en su primer número, decía que "alborea una España nueva... los españoles... siéntense preocupados por los temas vitales... Entre ellos figura en primer término el problema sexual, principio y fin de todos los problemas, porque encierra en su arcano todas las máximas o mínimas posibilidades de la raza y de la especie un tema vital que preocupa a los españoles" (Álvarez, 2004:70). Para los miembros de esta Liga, la educación sexual era una pieza importante para conseguir hacer realidad el programa eugenista.

La educación sexual fue objeto de atención de otras instituciones y reuniones científicas, así, en 1930 la "Liga Española de Higiene Mental propuso, entre los problemas de discusión para el Congreso de 1932, el tema de la Educación sexual, por ser ésta una cuestión de

Valencia, Tip. P. Quiles, editada por la publicación quincenal Cuadernos de Cultura, n XXXII, en 1931; Educación sexual. Madrid: s.n., 1931; El problema sexual tratado por una mujer española. Madrid, Morata, 1931; La rebeldía sexual de la juventud. Madrid, F. Peña Cruz, 1931 o "Maternidad Consciente", en Noguera (1934), p. 201-244. 
gran importancia y que interesaba a médicos, pedagogos, filósofos, juristas y psiquiatras", ${ }^{\natural 2}$ La preparación de este Congreso está en el origen de varias publicaciones de Lafora.

También el anarquismo planteó la cuestión sexual como parte de una problemática política más amplia. El pensamiento anarquista español elaboró una nueva ética sexual contrapuesta a las de la iglesia católica y a la moral sexual tradicional por considerarla represiva y distorsionadora de la sexualidad humana (Nash, 1993:640). Defendió la igualdad sexual y la libertad individual y puso énfasis en la educación (Seoane, 2006:161). Desde la revista anarquista, de aparición mensual, Generación Consciente. Revista ecléctica (19231927) se abordaron estas cuestiones y su sucesora, Estudios. Revista ecléctica publicada en Alcoy y Valencia (1928-1937), incluyó una proporción de artículos sobre las cuestiones sexuales muy superior a cualquier otra temática, lo que permite constatar las diversas posturas, discusiones y debates al respecto, pues entre sus colaboradores habituales había partidarios y adversarios de la Liga para la Reforma Sexual. Esta revista incluyó, además, un Consultorio psíquico-sexual $^{6}$ desde enero de 1936 , atendido por el psiquiatra y anarquista, Félix Martí Ibáñez, quien había empezado a colaborar en ella en 1934.

No es extraño, por tanto, que se produjera una eclosión de publicaciones en torno al sexo en las primeras décadas del siglo XX, evidenciándose un especial interés por los aspectos pedagógicos, lo que dio lugar a la aparición de la denominada educación sexual. Convenimos con Vázquez y Moreno (1997:132) en la división en tres etapas del desarrollo de lo que denominan "sexo-pedagogía":

- La primera etapa la sitúan en las dos primeras décadas del siglo $\mathrm{XX}$, un periodo en que apareció la literatura especializada, al traducirse importantes obras extranjeras y publicarse las primeras monografías y ensayos sobre educación sexual, como los de Genaro González Carreño, Antonio Piga o Lucien Mathé y se creó el citado Instituto de Medicina Social en 1919.

- La segunda etapa se corresponde con los años veinte, década en la que se incrementó el género sexológico y empezó el adoctrinamiento público (en la prensa, en la tribuna,

\footnotetext{
5 P. 5 Lafora, Gonzalo R (1933): La educación sexual y la reforma de la moral sexual. Madrid: Publicaciones de la Revista de Pedagogía. Esta obra junto con otra de Margarita Comas sobre coeducación fue editada en Buenos Aires en 1947, llegando en 1967 a la quinta edición (Lafora y Comas 1967).

${ }^{6}$ Véase Martí Ibáñez, Félix (1976): Consultorio Psíquico-Sexual. $2^{\mathrm{a}}$ ed. Barcelona: Tusquets y el prólogo de Ignacio Vidal; así como Navarro Navarro Francisco Javier (1997). "El Paraíso de la razón”. La revista Estudios (1928-1937) y el mundo cultural anarquista. València: Edicions Alfons el Magnànim.
} 
en la cátedra, en el libro, en el teatro, en la radio,...) al tiempo que las revistas citadas y otras de carácter educativo incluyeron artículos e información sobre esta cuestión ${ }^{7}$, no siendo extraño, por tanto, que se hablara de una cruzada de los reformadores sexuales.

- La tercera etapa la hacen coincidir con la II República, cuando se produjo un cambio cualitativo en el programa de reforma sexual orientado hacia una regeneración moral y se esperaba una legislación apropiada para ello. Un primer intento fue el del diputado César Juarros que planteó una enmienda para incorporar un artículo adicional en la Constitución, demandando que se legislase en defensa de la salud pública y de la educación física, educación sexual, etc. En su exposición planteó esta última como un tema moderno en la educación y que la incultura en materia de higiene provocaba casos como el de "esos matrimonios que, después de tener doce o catorce hijos, logran salvar la vida de uno solo, no consiguiendo sino la extenuación de la mujer, sin fruto para la sociedad, ni para el hogar" ${ }^{\prime 8}$. Le respondió desde la tribuna Jiménez de Asúa diciendo que nadie se oponía a esas doctrinas pero que se consideraba que debían formar parte de otras leyes. Al no ser apoyado retiró su enmienda e insistió en que la salud pública era una cuestión constitucional y un problema urgente por lo que esperaría con paciencia a esa ley futura. Un par de años después, la Liga Española de Higiene Mental presentó el proyecto de ley sobre pedagogía sexual que tampoco fructificó, debido al cambio de gobierno. Sin embargo, a pesar de no poder introducir cambios legislativos, las publicaciones sexológicas siguieron incrementándose ${ }^{9}$, quizás reforzadas por la labor divulgadora de estas asociaciones amparadas por este nuevo régimen político con ansias de modernidad.

\footnotetext{
7 Vasconcellos, Faria (1925): “La Educación Sexual”. En: Revista de Pedagogía, no 4, pp. 18-23; Bargallo, M. (1926): "Higiene Sexual del Hombre por E. Pozner". En: Revista de Escuelas Normales, vol. IV, no 35, p. 187; "Sobre la Ilustración Sexual de los Alumnos" (1928). En: Revista de Pedagogía, no 76, pp. 182-183; Ballesteros, 1928; Zulueta, 1929. También aparecieron obras destinadas a describir y canalizar la educación sexual de los hijos, como la del médico Director de la Escuela Central de Anormales y profesor de Psiquiatría en el Instituto Español de Criminología de Madrid, César Juarros, Normas de educación sexual y física, publicada en la colección "La salud de nuestros hijos" de la editorial Renacimiento, en 1925.

${ }^{8} A B C$ del sábado 28 de noviembre de 1931, p. 22.

${ }^{9}$ Son ejemplos Lafora (1932), Rodríguez (1933) o Garma (1934). A la difusión de estas cuestiones siguieron contribuyendo las reseñas bibliográficas como la de la obra de Boven (DR.W.): Adam et Eve ou la question des sexes.- Delachaux et Niestlé. Neuchatel, París, 1933, en: Revista de Pedagogía, $\mathrm{n}^{\circ}$ 137, 1933, pp. 233-234.
} 
La reforma sexual así planteada llevó a que los hombres continuaran con privilegios -no deseaban revolucionar las relaciones de género, pues su proyecto respetaba la supremacía masculina-, lo que provocó que los problemas de fondo de las mujeres en su experiencia con la sexualidad quedaran, en palabras de Nerea Aresti, "sacrificados a imágenes idealizadas de lo que supuestamente era bueno para ellas" (2002:148). La propuesta de una educación sexual eugénica es interpretada, por la citada autora, como un mecanismo de regulación de la población con efectos disciplinarios, pues interviene y repercute en la demografía, la salud y la herencia biológica. No se trataba ya de vigilar y corregir al individuo para evitar los males colectivos sino de encauzar el comportamiento. "Los modernos moralistas estaban proponiendo la sustitución de los dictados de la Iglesia Católica, que tenían en la castidad su más emblemática expresión, por un nuevo ideal de moderación y control racional de los impulsos sexuales. Lemas tales como “¡Sé cauto, no casto!” reflejaban el espíritu de aquellos intentos transformadores" (Aresti, 2002:126). Las enseñanzas sexuales producen efectos a escala individual pues consiguen modificar comportamientos individuales y qué mejor manera que hacer que cada escolar y cada maestro "transforme su modo de conducirse en relación con el cuerpo y sus placeres” (Vázquez y Moreno, 1997:169).

Veamos, pues, cuál fue el desarrollo en España de la educación sexual de niños y jóvenes.

\section{3. ¿Cómo abordar la educación sexual durante la infancia?}

Afirmaba el psiquiatra Garma que “después de años de lucha, la existencia de la sexualidad infantil ha sido aceptada por la mayoría de médicos y pedagogos" (1934:99), que dilucidaban quién, cómo y cuándo responder a las preguntas de los niños, si los padres o los maestros.

\subsection{La educación sexual en la familia}

Todas las voces que pedían romper la conspiración de silencio que dominaba en la sociedad (Ballesteros, Lafora, Garma, Hildegart,...) estaban de acuerdo en que el inicio de la enseñanza debía empezar en la familia. Si ésta estuviera preparada para realizar esta función debía proporcionar una ilustración apoyada en la ciencia, aunque para algunos esa explicación 
debía estar orientada, además, por los preceptos de la iglesia católica, que apostaba por una orientación claramente natalista para evitar el malthusianismo. Algunas voces reconocían que había cierto riesgo en que las explicaciones que se diesen fuesen imperfectas o inadecuadas por haber mantenido previamente silencio al respecto y que lo correcto sería responder con veracidad a sus preguntas desde el primer momento.

Entendían que esta información inicial debía darse de forma casual, es decir, respondiendo ocasionalmente desde los primeros años, cuando los niños en el período interrogativo hacen preguntas sobre su origen y nacimiento, respondiendo los padres de manera adecuada a la inteligencia infantil, sin contarles "esas ridículas fábulas de la cigüeña, de la fábrica de París o del pozo. Hay que decirles la pura verdad de una manera comprensible, explicándoles biológicamente el origen de la vida con ejemplos tomados de la naturaleza en la vida vegetal, animal y en el hombre" (Lafora 1932:487-488).

También recomendaron a los padres que no reprimiesen las tendencias sexuales que manifestasen los niños, que fuesen tolerantes, que no culpabilizasen esos comportamientos, pues, de hacerlo, podían provocar futuros trastornos en el niño, puesto que "la educación sexual de la infancia no es más que un segmento o eslabón de una cadena de problemas de conducta, referentes a la vida sexual en las edades posteriores de la vida, la cual está sometida fundamentalmente a un sistema de ideas morales, a una filosofía y a una ética" (Lafora, 1932:481).

Dentro de la familia, varios médicos y maestros, apelaban a que esta información la diese la madre, si bien denunciaban que muchas mujeres habían recibido escasa o nula formación general y carecían de una adecuada información sexual, por tanto, consideraban necesario empezar por cambiar la formación de las niñas, por promover escuelas de maternidad, cursos para matrimonios, etc.

En este sentido, la maestra anarquista Antonia Maymón decía que era necesario que "la futura madre reciba la especial y necesaria educación que le es indispensable para ser la educadora de sus hijos, misión única y exclusivamente suya y no del padre, ni del maestro, como hasta ahora se había creído" (1929:4). La madre debía conocer lo suficiente para responder a las preguntas de sus hijos "en la edad preescolar, esto es, la fase biológica inicial, pues ya mucho antes de los seis años se marcan en los niños las primeras manifestaciones de su carácter y actitud respecto a lo sexual (agresividad, timidez, vergüenza, hipocresía, franqueza, 
etc.) y si en este tiempo no se procede con tacto se dificultará después la labor educativa del maestro" (Lafora, 1932: 482).

Dada la diversidad de grados o niveles educativos que tenían los padres y la dificultad de que todos ellos estuvieran formados y capacitados para abordar la educación sexual en el ámbito familiar, y hasta que estos no supieran afrontar esta cuestión, se vio "conveniente que la educación fundamental del niño con respecto a la sexualidad sea dada por el maestro que dirige la educación total" (Lafora, 1932:482). No obstante, también denunciaban que el silencio acerca de esta cuestión había alcanzado a la escuela. "Nuestros maestros tienen la misma preparación - es decir, ninguna- sobre este aspecto básico de la cultura que los padres, a no ser que hayan buscado en un trabajo personal un conocimiento que debería ser indispensable para ejercer la enseñanza” (Ballesteros, 1928: 537).

\subsection{La educación sexual desde la escuela}

Para los eugenistas españoles y para los miembros del citado Instituto de Medicina Social cualquier foro era bueno para difundir sus planteamientos, pues tenían un amplio sentido de lo que era la enseñanza y por eso acudían a cualquier lugar desde el que ejercer un influjo educador (ateneos, teatros, radio, institutos,...), incluida la escuela.

Ya en 1918, Huerta Naves afirmaba que era necesario intercalar la educación sexual "en los programas de estudios de nuestras escuelas de niños y niñas y en todos los centros de cultura popular, secundaria y universitaria” (Huerta, 1918:75), pero diez años después aún se afirmaba que el tema sexual había sido deliberadamente excluido de la enseñanza primaria ${ }^{10}$. Huerta insistió nuevamente en que la escuela primaria, como institución universal de cultura, tenía "un papel claramente definido: la educación preparatoria para la vida sexual sana y normal" (1934b:154-155). Maestras y maestros debían intervenir para encauzar, en el momento adecuado, el instinto sexual que se manifiesta en la niñez.

En síntesis, dos objetivos tenía la educación durante el periodo de escolarización: el niño debía comprender la relación de la función sexual con el bienestar del individuo, de la familia y de la sociedad y aprender a protegerse de los riesgos derivados del vicio y de la función sexual prematura o desordenada.

\footnotetext{
${ }^{10}$ Véase, por ejemplo, Ballesteros (1928:588) o Rodríguez (1933:337).
} 
El magisterio tenía ante sí otro reto: formar a las mujeres para que iniciaran adecuadamente la educación sexual de sus hijos, pues como afirmaba la maestra Herminia García, Directora del grupo Escolar "Concepción Arenal” de Madrid, los mejores rendimientos se conseguirían "empezando por enseñar a las madres el cuidado de sus hijitos aún antes de nacer" (Semana, 1930:36), para ello se aprovecharían las clases para adultas o las conferencias dominicales.

A las maestras se les encomendaba una tarea educadora mayor, en la medida en que "la mujer debe preparase en la niñez para cumplir conscientemente el tripe papel meritísimo de AMA, ESPOSA y MADRE” (Huerta, 1930a: 67), se responsabilizaba más a las mujeres de la degeneración y enfermedad de la prole porque, en palabras del médico Enrique Diego Madrazo, "nada vendrá que no haya estado presente en la impregnación sexual ..., todo pasó antes por el vientre de la mujer" (prólogo Huerta, 1930a:11).

Las maestras destinadas en las zonas rurales debían abordar igualmente la formación de las mujeres, pues "nadie como la maestra rural, inteligente y buena, para hablar a las madres, con lenguaje claro y noble, sobre los estragos de la herencia biológica manchada en los manantiales de la vida por la contaminación de morbos destructores" (Huerta, 1934a:296). Las maestras debían conocer bien la técnica del Birth Control para enseñar a las mujeres de los pueblos en los que ejercieran.

Sin embargo, la educación sexual convenía por igual a ambos sexos dado que "la mujer no puede hacer más que un hijo en nueve meses, y el hombre puede engendrar uno cada día" (Madrazo, 1932, 263). Por eso la maestra asturiana $\mathrm{M}^{\mathrm{a}}$ Josefa Varela afirmaba rotundamente que "la educación sexual no es nada si no reconoce el valor de la eugénica, que es ciencia fundada en la biología de los sexos o sexología y en la herencia física o genética" (Varela, 1932:237).

\subsubsection{La necesaria formación del magisterio}

"Para llevar hoy a cabo una verdadera educación sexual del niño es, pues, necesaria la "ilustración sexual" del adulto, es decir, de los maestros, padres y demás personas que entran en contacto con el niño", decía Lafora (1933: 27). Los maestros en activo o en formación no 
eran una excepción ${ }^{11}$, pues no habían recibido una formación específica para abordar la educación sexual de los escolares, por eso debían formarse de manera autónoma y para ello era útil, según recomendaban Ballesteros (1928) y Lafora (1932), la lectura de las obras de Gregorio Marañón, en especial Tres ensayos sobre la vida sexual y La educación sexual y la diferenciación sexual.

Fue durante la segunda década del siglo XX cuando se comenzó a reclamar que el magisterio introdujera estas enseñanzas, pues era una forma de aplicar la "eugénica preventiva", con el fin de conseguir una "eugénica positiva", es decir, una paternidad buena, una descendencia sana. Para ello, médicos y maestros intentaron modificar la formación inicial del magisterio incorporando nuevos conocimientos y, entre ellos, específicamente la educación sexual. Veían necesario introducir la enseñanza de la eugénica en las Escuelas Normales dado que en ellas se "forma el magisterio primario, cuya misión es llevar a los más apartados rincones del país los fundamentos de la cultura humana" (Huerta, 1934a:296), de esta manera los nuevos maestros transmitirían estos conocimientos del modo adecuado tanto a los escolares como a los padres que lo necesitasen.

El diseño del plan de estudios de maestro que hizo la República en 1931 no satisfizo las demandas de los eugenistas pues "en el nuevo plan hay mucha metodología de asignaturas y escaso conocimiento básico del alumno" (Huerta, 1934a:301) y la educación sexual no se consiguió introducir en el programa de las Escuelas Normales ${ }^{12}$.

No obstante, hubo otras vías para formar tanto al magisterio en activo como a quienes se estaban formando, por ejemplo, la lección que impartió la profesora uruguaya Paulina Luisi sobre esta cuestión en el Ateneo de Madrid en enero de 1934. En la crónica periodista se dice que para evitar todo equívoco aclaró el concepto de educación sexual "en el que nada hay de truculento, malicioso, ni pornográfico, y sí una reivindicación social que eleva de conceptuación a la mujer y la dignifica por ser madre"13. En esta sesión presentó el material cinematográfico con el que en Urugay se formaba a las maestras y a las niñas del último curso de la enseñanza primaria y terminó “aconsejando al magisterio que estas lecciones se den en la

\footnotetext{
${ }^{11}$ Sólo en el plan de estudios de las Escuelas Normales 1914 se introdujo la asignatura Fisiología e Higiene y ese mismo año también comenzó en la Escuela Superior del Magisterio la asignatura Higiene escolar a cargo de Luis de Hoyos, desde las que podían tratarse alguno de estos contenidos.

${ }^{12}$ No era el único contenido que se quiso introducir en la formación inicial, pues también decían "hay que solicitar con la urgencia precisa la incorporación de la inclusión de los estudios de Medicina escolar en la carrera del Magisterio" (Semana, 1930:28).

${ }^{13}$ La libertad, $\mathrm{n}^{\circ} 4.322,31$ de enero de 1934, p. 7.
} 
escuela con naturalidad, sin afectación y sin miedo, de igual manera que se explica el aparato digestivo o la higiene de cualquier sentido".

\subsubsection{La publicación de obras para mejorar la formación sexual}

A principios del siglo XX empezó una preocupación por el cuerpo que, según $\mathrm{M}^{\mathrm{a}}$ del Mar del Pozo (2000:96), fue la gran innovación introducida en la enseñanza primaria. Este interés se plasmó en el curriculum escolar con la introducción de la educación física y la enseñanza de la Fisiología e Higiene, declaradas materias obligatorias en 1901 y en estas asignaturas se inculcaban hábitos higiénicos y saludables en la vida de los niños pero no incluían las cuestiones sexuales.

La falta de libros sobre sexualidad apropiados para uso escolar fue paliada por varias instituciones como la Sociedad Española de Higiene, que había iniciado su andadura en 1881 y entre sus objetivos tenía el "propagar los conocimientos higiénicos, crear institutos de higiene, fomentar esta disciplina desde el punto de vista de la docencia y de la investigación y el de confeccionar una estadística demográfico-sanitaria"14. Para difundir la higiene convocó varios concursos, abordando específicamente el de 1911 favorecer la difusión de la educación sexual. Ese año, uno de los premios Roel, dotado con 500 pesetas, tenía que abordar el tema "Programa mínimo de higiene sexual para las escuelas de niños y niñas". A los autores se les indicaba que las memorias debían "estar escritas teniendo en cuenta que su principal objeto es la propaganda y vulgarización científica, para que puedan estar al alcance de las personas de mediana o escasa ilustración" ${ }^{15}$. En la convocatoria se decía que los textos podían estar escritos, además de castellano, en francés o italiano. Fue premiada, precisamente, la memoria presentada por el francés Lucien Mathé, inspector de las escuelas de París, que se publicó con el mismo título de la convocatoria en castellano y, sorprendentemente, el texto en francés, lo que no parece que favoreciera la pretendida vulgarización de estos conocimientos. Esta es una de las primeras obras en abordar directamente la higiene sexual y la corporal, la moral, la iniciación, con lecciones específicas para chicos y chicas, la herencia, las enfermedades venéreas o cómo luchar contra el libertinaje.

\footnotetext{
${ }^{14}$ Reglamento de la Sociedad Española de Higiene: aprobado en la junta general que se celebró el día 19 de enero de 1883. Madrid: s.n.1883.

${ }^{15}$ Véase $A B C, 5$ de septiembre de 1911, p. 6
} 
Fue en 1922, cuando se publicó la primera obra que incluyó no sólo cuestiones de higiene y salud en un texto de lectura escolar sino también un capítulo referido específicamente a la eugenética. Su autor fue Ángel Santos Vila, quien narra en el prólogo que su obra "tuvo su origen en la base $7^{\circ}$ del VIII concurso de premio del Consejo Superior de Protección a la Infancia y Represión de la Mendicidad. Se respetaba a los concursantes la libre elección de tema para hacer un trabajo de «popularización de asunto higiénico-pedagógico», y se señalaban normas que era preciso observar" (Santos, s.f.:7). Con la obra titulada Por la raza. Para ser sanos y fuertes. Tabaquismo, alcoholismo, tuberculosis, eugenética. Lecturas de popularización higiénico-social, obtuvo un Diploma de Mérito y fue elogiada por su claridad y brevedad y por ser apropiada para $\operatorname{los}$ niños ${ }^{16}$ en la reseña que le hizo Pablo Miaja en 1923. La obra tuvo éxito pues algunos ayuntamientos la adquirieron para premiar a los alumnos, como el de Gijón, que entregó un ejemplar a cada uno de los 25 mejores estudiantes del curso 1924/25; también fue recomendada para el tercer grado de la enseñanza primaria por algunos inspectores ${ }^{17} \mathrm{y}$, además, fue reeditada en tres ocasiones (y a esta tercera edición ilustrada están referidos los entrecomillados que siguen). El propio autor finaliza el prólogo dando cuenta de este éxito "al reiterar las gracias de la primera edición al Consejo Superior de Protección a la Infancia y Represión de la Mendicidad por la distinción concedida a este modesto trabajo, cúmpleme hacerlas extensivas al profesorado, a la Prensa y al público en general por su buena acogida".

Santos Vila, confiesa en el prólogo que el capítulo de eugenética fue el más difícil de escribir, que fue cauteloso y midió sus palabras "porque aun hay gentes que gustan de una educación hipócrita y falseada que oculte verdades manifiestas”. Esta obra va destinada a un uso escolar, pero dice que también es útil en las clases nocturnas de adultos y en los hogares. Recomienda que la lectura de estas páginas sea "razonada, reflexiva, comentada" y, dirigiéndose específicamente a los varones, dice: "Tú lee todo este capítulo y al final elabora la definición que te plazca. Conviene que te acostumbres a construir ideas por tu cuenta, y no todas a recibirlas hechas". Básicamente en estas páginas dedicadas a la eugenética reflexiona y da consejos sobre la importancia de ser responsables en la procreación, de estar sanos para procrear sano. Dirigiéndose a los jóvenes escribió “Conviene que tú seas lo más perfecto que sea dable, y que te afanes por tu perfección. De esta manera podrás optar con derecho a una

\footnotetext{
${ }^{16}$ Véase Revista de Pedagogía, no 35, 1923.

${ }^{17}$ Marcos Rodríguez, Ernesto (1925): "Sobre el libro escolar". En: Revista de Pedagogía, no 41, p.207.
} 
mujer perfecta (...) Si por desgracia te sobreviniese alguna enfermedad transmisible, no debes casarte para no incurrir en la tremenda responsabilidad que tamaño crimen implica (...), de ti y de tu compañera depende que tengas una generación, una descendencia normal, equilibrada, sana" (p. 83-87), afirmando que los hijos heredan fatalmente las buenas y malas cualidades de sus padres y apelaba a la responsabilidad individual: "no digas como el ignorante dice: sea lo que Dios quiera. Haz porque Dios quiera que sea lo que tú quieras (...) tú debes procurar dar a la sociedad y a la Patria hombres dignos de la ilimitada perfección y continuidad histórica" (p.86).

La dictadura de Primo de Rivera no había prestado atención a los libros de enseñanza primaria, en cambio el gobierno republicano convocó un concurso para seleccionar obras de lectura que fueran apropiadas para uso escolar, por reunir las necesarias condiciones pedagógicas, científicas y literarias al que se presentó esta obra de Santos Vila, que fue aprobada para uso en las bibliotecas escolares por la orden del 17 de mayo de 1934, conservando la aprobación en la orden de 5 de febrero de $1936^{18}$. En plena guerra civil los editores que querían seguir publicando libros para la enseñanza primaria tenían que presentar dos ejemplares al Ministerio de Educación Nacional para que una vez examinados fueran declarados aptos para la enseñanza oficial y lamentablemente, esta obra fue prohibida en 1938 precisamente "por contener expresiones duras en el capítulo «Eugenesia»" ${ }^{19}$ y ya no hay noticias de ella durante la dictadura franquista.

La convocatoria de premios parece que fue la mejor vía para publicar sobre educación sexual de la infancia pues, en 1929, la citada Sociedad Española de Higiene convocó, como era habitual, varios premios y uno debía tener como tema "Enseñanza de la Higiene sexual en las escuelas. Desarrollo de esta materia en un programa pedagógico que armonice las necesidades de la Instrucción con los sentimientos morales y religiosos que debe inspirar toda obra educadora" ${ }^{20}$. Este premio, subvencionado por el general Martínez Anido, entonces Ministro de Gobernación, recompensaba a los autores seleccionados con mil pesetas, diplomas de socio correspondiente, accésits y menciones honoríficas. Además, cada uno de los trabajos

\footnotetext{
${ }^{18}$ Véase Gaceta de Madrid del 18 de mayo de 1934 y la del 21 de febrero de 1936.

19 Véase el acta de la sesión celebrada en Vitoria el 28 de septiembre de 1938 por la Comisión Dictaminadora de Libros de Texto que se han de usar en las escuelas nacionales, en la Caja 6.085 del Archivo General de la Administración. Casi dos años más tarde, la Dirección General de Primera Enseñanza publicó en el Boletín Oficial del Ministerio de Educación Nacional del 15 de abril de 1940 la relación de las obras no aprobadas.

${ }^{20}$ Véase La vanguardia, jueves 10 de octubre de 1929, p. 21.
} 
premiados sería publicado por el Ministerio de la Gobernación, que entregaría al autor 300 ejemplares de una tirada de 500. Los premios se hicieron públicos el 24 de enero de 1930 en el Colegio de Médicos ${ }^{21}$, obteniendo el primero José Bugallo Sánchez, por su obra La higiene sexual en las escuelas y el accésit Luis Huerta por su obra La educación sexual del niño y del adolescente.

Bugallo, Delegado del Tribunal Tutelar para Niños de Madrid, no consiguió cobrar el premio viéndose obligado a acudir a los tribunales, y así lo cuenta a los lectores al publicarse la obra. En ella señala que si se pone en práctica la educación sexual de la infancia como parte que es de la educación general, traerá varias ventajas: contribuir a mejorar la raza, prevenir males venéreos, neurosis y perversiones, evitar la mortalidad juvenil y mejorar la moral y el bienestar social y racial y "habría mayor respeto a la mujer, mayor cariño a la madre, mayor amor a la compañera, mayor interés por la progenie" (1930:15). En la primera mitad de la obra justifica la enseñanza de la higiene sexual, dedicando un capítulo a recoger las alusiones hechas en la Biblia, las de los Santos Padres, las de Ruiz Amado y Manjón, entre otros, en favor de esta educación y la otra mitad son lecciones sobre botánica, zoología y fisiología para niños y niñas, y la octava está dedicada específicamente a ellas. Lafora (1932:489) aconsejaba la lectura de esta obra a padres y maestros.

La obra de Huerta, según advierte al comienzo del libro, es un texto que había sido pensado hacía tiempo y que había terminado de escribir el 8 de marzo de 1921, día de su cumpleaños. Por el prólogo de Diego Madrazo sabemos que su título original era Vida sexual: lecturas eugénicas para el grado superior de la instrucción primaria y que no había conseguido publicarla, por lo que decidió participar en el citado concurso de 1929 obteniendo el accésit. La obra consta de 11 lecciones sobre la reproducción humana, los enemigos de la raza, el matrimonio, la paternidad, la progenie,... Al final de esta obra aclara que está redactada para ser utilizada en las escuelas, tal y como requería la convocatoria del concurso, pero si se tratara de integrar esta formación en la segunda enseñanza "había que darle un carácter más científico y de mayor rigor lógico en la exposición del tema de la Higiene Sexual” (1930a:71) y para ello suscribe y recoge el programa que desarrolló el Dr. Renato Kehl en Río de Janeiro y que había presentado al Primer Congreso Nacional de Educación celebrado en la capital de Brasil en 1928.

\footnotetext{
${ }^{21}$ Véase $A B C$ del 25 de enero de 1930, p. 23.
} 
Esta obra fue reseñada en tono muy elogioso, considerándola un acierto pues la educación sexual estaba descuidada en España y en ella se hermanaba, "el talento del educador, con las ideas del fervoroso eugenista y con los méritos del buen escritor, maestro en el arte del buen decir y cultor afortunado del difícil arte de escribir con concisión y claridad sin que por ello adolezcan sus bellos escritos de aridez, sequedad o inelegancia"22.

No tenemos noticia de la publicación de más obras destinadas a la enseñanza primaria. En las descritas se abordó específicamente la eugenética y la educación sexual, sirviendo de indicación a progenitores y docentes para afrontar la educación sexual de la niñez.

\subsubsection{La aclaración sexual y la coeducación}

Aunque según Ballesteros (1928:588) el tema sexual había sido deliberadamente excluido de la enseñanza primaria, sí que hubo desde principios de siglo recomendaciones concretas de cómo abordar estas enseñanzas. La "aclaración sexual", es decir, informar al escolar en el momento oportuno de estas cuestiones, una técnica que según el psiquiatra Ángel Garma, utilizaban los pedagogos alemanes es a la que más aluden médicos y pedagogos españoles.

Según Lafora esta instrucción sexual "tiene dos etapas distintas: una, biológica, que debe iniciarse en el niño antes de la pubertad y continuarse en ésta, y otra, social y filosófica, que corresponde al periodo posterior a la pubertad, entre los catorce y los veintiún años” (1932:483) y recomienda para iniciar a los niños o adolescentes en los misterios de la reproducción y de la sexualidad varias obras, pero sólo una en español: la de Juan Manuel Zapatero, Pedagogía sexual. Lo que se debe saber (1932:489).

El modo en que cada educador desarrollara esta técnica podría variar, pero todos deberían partir de un punto común: al niño que llegaba a la pubertad no se le debía dejar en la ignorancia de los problemas sexuales, también consideraban negativo dar esa explicación a los diez o quince años -que era lo habitual en aquel tiempo- porque la aclaración debía hacerse desde el primer momento que el niño demostrara interés por cualquier aspecto sexual, respondiendo a cada pregunta que hiciera con veracidad.

La “sexuelle Aufklärun”, esto es, la revelación, aclaración o ilustración sexual de la infancia planteaba grandes dificultades, pero debía, "ante todo, ser igual para los muchachos de

\footnotetext{
${ }^{22}$ Véase la reseña de H[iginio]. N[oja]. R[uiz]. En: Estudios. Revista ecléctica, no 88, diciembre 1930, pp. $39-40$.
} 
ambos sexos" (Lafora, 1932:485). El principal problema que se planteaba era elegir bien el momento, pues "en primer lugar, tengamos en cuenta que si una advertencia parece improcedente cuando el instinto sexual no ha despertado todavía, es lo cierto que una perversión sexual puede nacer o despertar antes de establecerse la función. En segundo término: lo sospechado ¿no será más nocivo que lo aprendido?” (Gomilá, 1927:271), por eso decía "lo que llamamos educación sexual debe ser más una advertencia que una enseñanza. No se trataba de ilustrar al niño en una función mecánica, sino de imbuirle nociones de defensa e ideas de resistencia, infundiéndole al propio tiempo la del alcance moral, individual y social de lo que pertenece a la generación" (Gomilá, 1927:271). El cómo y el cuándo de la advertencia eran, pues, lo esencial e insistían en que los que estaban en mejores condiciones de aclarar estas cuestiones a los menores eran los padres y los maestros.

Lafora afirmaba que la ilustración sexual biológica debía iniciarse poco antes de la pubertad, "entre los nueve y diez años y corresponde principalmente al maestro. A la niña hay que prevenirla antes de que la realidad pueda sorprenderla sobre la existencia y finalidad de sus periodos menstruales y al niño sobre lo fundamental de la vida sexual, su función, sus peligros y su higiene" (1932:488). Otros, como Ballesteros distingue entre enseñanza y educación sexual, planteando la necesidad de una enseñanza sistematizada y científica en la que los escolares estudiasen "las características fisiológicas de los sexos, su higiene, los problemas relacionados con la futura vida sexual y sus peligros, el tema de la castidad, los problemas del nacimiento y la crianza de los niños, el de las uniones, etc.., etc. Estos temas pueden tener su lugar en los programas de fisiología, higiene, historia natural, etc., sin darle un carácter separado y especial" (1928:541). Para él, la educación sexual tiene mayor trascendencia y plantea más dificultades y para hacerla efectiva apela a una forma general de educación y organización escolar: la coeducación.

Son varios los reformadores que invocaban la coeducación como uno de los medios más importante de la educación sexual, entendiendo que no se trataba sólo de que ambos sexos estén juntos en el aula "sino la formación continuada de un concepto del mundo, de un ideal de vida en ambos sexos conjuntamente" (Lafora, 1932:546). La coeducación originaría sentimientos de respeto mutuo y de camaradería, poniéndose en evidencia la igualdad intelectual de ambos sexos por estar sometidos a iguales condiciones de esfuerzo mental.

No faltaron voces de quienes aceptando la coeducación creían necesario una educación específica que preparara a las niñas para su deber natural: la maternidad. El profesor de la 
Escuela Superior del Magisterio Zulueta planteaba que "las niñas no deben educarse como los niños. Cada uno de los dos sexos ha de recibir una formación diferente $\mathrm{y}$, en cierto sentido, opuesta. Pero si las niñas no deben educarse como los niños, acaso deban educarse con los niños” (1929: 244). La maestra racionalista Antonia Maymón señalaba el porqué de esa diferencia: "las niñas tienen necesidad de una educación especial para prepararse al gran deber, que la naturaleza les ha impuesto, con la maternidad" (1929:4), considerando urgente implantar como asignatura en las escuelas primarias la enseñanza de la maternología (Maymón, 1926: 213).

\section{Conclusiones}

Aquella reforma sexual que se planteó en el primer tercio del siglo XX y que abogaba por una educación sexual de la infancia tanto en la familia como en la escuela no llegó a buen puerto en cuanto a su incorporación en el currículo. Planteaban la educación sexual esencialmente como un instrumento de mejora de la salud y de regulación del comportamiento sexual que requería que los adultos procrearan menos y mejor $\mathrm{y}$, en ese discurso, responsabilizaban sobre todo a la mujer.

Las iniciativas divulgadoras desarrolladas, las obras específicas destinadas a la infancia o al magisterio, los artículos en la prensa diaria o en las revistas especializadas sólo paliaron el vacío pero no sirvieron para generar una corriente a favor de la educación sexual en la escuela o la adhesión de suficientes maestras y maestros próximos a los núcleos de difusión ni de los que residían en zonas más alejadas que tenían más dificultad para acceder a esa información y esos conocimientos. Quizá influyera, como declaraba Juarros, que muchos educadores, padres y médicos confundían los conceptos de instrucción sexual y educación sexual, lo genital con lo sexual y así sostenía que "son mayores los daños causados a la noble causa de la infancia por quienes pretenden realizar educación sexual, que por aquellos otros tímidos, egoístas o discretos dispuestos a ignorar el problema" (1933:1139).

En la actualidad, la educación sexual de los escolares continúa siendo una asignatura pendiente, que aún depende del interés y la capacidad de maestras y maestros para abordar esta formación o espera que asociaciones u organismos ajenos a la escuela se acerquen a ella para 
formar e "informar" esporádicamente sobre aspectos sanitarios (contagio de enfermedades, anticoncepción...).

\section{BibLIOGRAFÍA}

- Álvarez Peláez, Raquel (1985): “Introducción al estudio de la eugenesia española (19001936). En: Quipu, vol. 2, nº1, pp. 95-122.

(1988): "Instituto de Medicina Social. Primeros intentos de institucionalizar la eugenesia”. En: Asclepio. Revista de Historia de la Medicina y de la Ciencia, vol 40, nº 1, pp. $343-358$.

. (2004): “Félix Martí Ibáñez y la eugenesia en España". En: Martí Boscá José Vte. y Rey González, Antonio: Actas del I Simposium Internacional Félix Martí Ibáñez. Valencia: Generalitat valenciana. Conselleria de Cultura, Educació i Esport. 57-76.

- Aresti, Nerea (2002): La nueva mujer sexual y el varón domesticado. El movimiento liberal para la reforma de la sexualidad (1920-1936). En: Arenal, vol. 9, nº 1, pp. 125-150.

- Ballesteros, Antonio (1928): “Sobre educación sexual”. En: Revista de Pedagogía, nº 84, pp. 536-545.

- Barrachina, Marie-Aline (2004): "Maternidad, feminidad, sexualidad. Algunos aspectos de las Primeras Jornadas Eugénicas Españolas (Madrid, 1928 - Madrid, 1933)”. En: Hispania, nº 218, pp. 1.003-1.026.

- Bugallo Sánchez, José (1930): La higiene sexual en las escuelas. Madrid: Javier Morada, editor.

- Cura, Mercedes del y Huertas, Rafael (2004): "Medicina y sexualidad infantil en la España de los años treinta. La aportación del psicoanálisis a la pedagogía sexual”. En: Hispania, nº 218, pp. 987-1.001.

- Garma, Ángel (1934): "Psicología de la aclaración de la sexualidad en la infancia”. En: Revista de Escuelas Normales, vol. 12, nº 103, pp. 98-103.

- Gomilá, Sebastián (1927): “La educación sexual”. En: Generación consciente. Revista ecléctica, $\mathrm{n}^{\mathrm{o}}$ 47, 270-271. 
- González Carreño, Genaro (1910): La educación sexual. Madrid: s.n

- Huerta, Luis (1928): "Primer curso eugénico español”. En: Revista de escuelas normales, $\mathrm{n}^{\circ}$ 51, p. 61-64.

- Huerta, Luis (1929a): Por qué los maestros queremos la colaboración de los médicos y de los arquitectos escolares. En: El Sol 2 de abril de 1929, p. 8. (También publicado en Puericultura, $\mathrm{n}^{\circ}$ 101, ese año).

. (1929b): "El hogar doméstico". En: Estudios. Revista ecléctica, no 73, septiembre, pp. 25-26.

(1930a): La educación sexual del niño y del adolescente. Madrid: Instituto Samper.

(1930b): "Los nuevos guías", en Estudios. Revista ecléctica, nº 85 septiembre, pp. 1617.

(1934a): "La eugenesia y la preparación del maestro". En: Revista de Pedagogía, no 151 , julio 1934 , pp. 296-301.

(1934b): "Pedagogía y Eugénica”. En: Noguera, Enrique y Huerta, Luis (Dirs.): Genética, eugenesia y pedagogía sexual. Libro de las primeras Jornadas Eugénicas Españolas. Madrid: Javier Morata, editor. T. II, 150-169.

- Huerta Naves, Luis (1918): Eugénica, maternología y puericultura. Ensayo de un estudio sobre estirpicultura o cultivo de la especie humana por las leyes biológicas; o sea, manera científica de engendrar y criar hijos sanos, buenos, listos y hermosos. Madrid: Imp. de Fortanet.

(1921): "La obra cultural de la escuela primaria". En: Asociación española para el Progreso de las Ciencias. Congreso de Sevilla. Madrid: Imprenta Clásica Española. T.II, 2529.

- Huertas, Rafael y Novella, Enric (2013): "Sexo y modernidad en la España de la segunda república. Los discursos de la ciencia”. En: Arbor. Ciencia, Pensamiento y Cultura, vol. 189 (764). A090. DOI: http://dx.doi.org/10.3989/arbor.2013.764n6013.

- Juarros, César (s.d.): Normas de educación sexual y física. Madrid: Renacimiento. (1933): "Normas básicas de la educación sexual”. En Orto. Revista de documentación social, $\mathrm{n}^{\mathrm{o}} 17$, pp. 1.139-1.144. 
- Lafora, Gonzalo R. (1932): “La educación sexual”. En: Revista de Pedagogía, no 131, pp. $481-490$ y no 132 , pp. 543-549.

- Lafora, Gonzalo R. y Comas, Margarita (1967): La educación sexual y la coeducación de los sexos. (5 $5^{\circ}$ ed.). Buenos Aires: Losada.

- Lázaro, Luis Miguel (2009): "Luis Huerta: eugenesia, medicina y pedagogía en España”. En: Historia de la Educación. Revista Interuniversitaria, nº 28, pp. 61-88.

- Lázaro Lorente, Luis Miguel (1996): “El debate acerca de la educación sexual en la España de los años treinta”. En: IX Coloquio de Historia de la Educación. El currículo: historia de una mediación social y cultural. Vol. 2. Granada: Osuna, 1996 p. 109-120.

- Maymón, Antonia (1926): “Desaparecerá la madre?”. En: Helios, n 125, octubre. . (1929): “Temas pedagógicos”. En: Estudios, n 67, marzo, p. 4.

- Madrazo, Enrique D. (1932): Pedagogía y eugenesia (cultivo de la especie humana). Madrid: Librería de los sucesores de Hernando.

- Martí Ibáñez, Félix (1937): “Sanidad, asistencia social y eugenesia en la evolución social española”. En: Estudios, no 160, enero, pp. 36-41.

- Mathé, Lucien (1911): Programa mínimo de Higiene sexual para las escuelas de niños y niñas. Madrid: Imprenta de los Sucesores de J. A. García.

- Nasch, Mary (1993): “Maternidad, maternología y reforma eugénica en España 1900-1939. En: Dubi, G. y Perrot, M. (Dirs). Historia de las mujeres en Occidente, t. IV, Barcelona: Círculo de Lectores.

- Noguera, Enrique y Huerta, Luis (Dirs.) (1934): Genética, eugenesia y pedagogía sexual. Madrid: Javier Morata, editor. 2 t.

- Piga y Pascual, Antonio (1910): Higiene de la pubertad. Toledo: Vd a e Hijos de J. Peláez.

- Polo Blanco, Antonio (2006): "El silencio de la pedagogía al comienzo del régimen de Franco". En: Historia Actual Online, n 10, pp. 87-95.

- Pozo Andrés, Ma del Mar de (2000): "Salud, higiene y educación: origen y desarrollo de la Inspección Médico-Escolar en Madrid (1900-1931)”. En: Áreas. Revista de ciencias sociales, no 20 , pp. 94-120. 
- Rodríguez, Gerardo (1933): "La educación escolar respecto a la función sexual”. En: La Escuela Moderna. Revista pedagógica y administrativa de primera enseñanza, $\mathrm{n}^{\circ}$ 503, pp. 337344.

- Santos Vila, A. (s.d.): Por la raza. Para ser sanos y fuertes. Tabaquismo, Alcoholismo. Tuberculosis. Eugenética. Lecturas de popularización higiénico-social (3 ${ }^{\mathrm{a}}$ ed. ilustrada). Burgos: Hijos de Santiago Rodríguez.

- Semana médico-pedagógica. Conferencias, visitas, documentos (1930): Madrid: Imprenta comercial.

- Seoane, José B. (2006): El placer y la norma. Genealogía de la educación sexual en la España contemporánea. Orígenes (1800-1920). Barcelona: Octaedro.

- Varela, María Josefa (1932): “Sexo y educación”. En Orto. Revista de documentación social, $\mathrm{n}^{\mathrm{o}} 4$, pp. 236-238.

- Vázquez García, Francisco y Moreno Mengíbar, Andrés (1997): Sexo y razón. Una genealogía de la moral sexual en España (siglos XVI-XX). Madrid: Akal.

- Zapatero, Juan Manuel (1922): Pedagogía sexual. Lo que se debe saber. Barcelona: Francisco Isart.

- Zulueta, Luis (1929): “La educación sexual”. En: Boletín de la Institución Libre de Enseñanza, no 832, pp. 242-244. 